\title{
Perioperative care of congenital adrenal hyperplasia - a disparity of physician practices in Canada
}

\author{
Munier A. Nour ${ }^{1 *}$ (D, Hardave Gill², Prosanta Mondal ${ }^{3}$, Mark Inman $^{1}$ and Kristine Urmson ${ }^{2}$
}

\begin{abstract}
Background: Congenital adrenal hyperplasia (CAH) due to 21-hydroxylase deficiency is the most common cause of primary adrenal insufficiency in children. Current guidelines recommend the use of perioperative stress dose (supraphysiologic) glucocorticoids for children with CAH undergoing anesthesia, although a perceived difference in practice patterns among Canadian pediatric subspecialists prompted an assessment of perioperative glucocorticoid administration.

Methods: We performed a cross-sectional survey of Canadian Pediatric Anesthesia Society (CPAS) and Canadian Pediatric Endocrine Group (CPEG) members via membership email lists to assess reported practice patterns to select clinical scenarios.

Results: Responses were collected from 49 anesthesiologists and 37 pediatric endocrinologists. Less than half of anesthesiologists reported they would provide stress dose corticosteroids for patients undergoing cystoscopy while a significant majority of pediatric endocrinologists reported they would recommend stress dose corticosteroid administration (45\% vs $92 \%$ respectively, $p<0.0001$ ). Twenty-one percent of anesthesiologists reported they would not provide stress dose corticosteroids for patients undergoing laparotomy. Pediatric endocrinologists reported they were more likely to refer to guidelines for management of stress dose steroids ( $84 \%$ vs $51 \%, p<0.001$ ), with many Canadian pediatric endocrinologists reporting to use institution specific guidelines.

Conclusions: Our results demonstrate a clear difference in the reported approach to perioperative stress dose steroids between pediatric anesthesiologists and pediatric endocrinologists which may impact patient care. Further dialogue is required to address this apparent discrepancy in practice patterns and future research is needed to provide evidencebased practice recommendations.
\end{abstract}

Keywords: Congenital adrenal hyperplasia, Adrenal insufficiency, Anesthesia, Glucocorticoid, Perioperative care

\section{Background}

Adrenal insufficiency due to classical 21-hydroxylase (21-OH) deficiency congenital adrenal hyperplasia (CAH) requires lifelong therapy with glucocorticoids and usually mineralocorticoids. The purpose of glucocorticoid therapy in 21-OH deficiency $\mathrm{CAH}$ is two-fold: to replace for the glucocorticoid deficiency and to suppress excess endogenous androgen production. While

\footnotetext{
* Correspondence: munier.nour@usask.ca

'Division of Pediatric Endocrinology, Department of Pediatrics, College of

Medicine, University of Saskatchewan, Royal University Hospital, 103 Hospital Drive, Saskatoon, SK S7N 0W8, Canada

Full list of author information is available at the end of the article
}

most conditions associated with adrenal insufficiency are treated with doses to approximate physiologic replacement [1], classic 21-OH deficiency $\mathrm{CAH}$ often requires mild supra-physiologic dosing $\left(10-20 \mathrm{mg} / \mathrm{m}^{2} /\right.$ day of hydrocortisone equivalent) to prevent virilisation by androgen excess and reduce the risk of adrenal crisis [2, 3].

Current practice guidelines for the treatment of primary adrenal insufficiency advocate for the use of stress dose supraphysiologic corticosteroid treatment during intercurrent illness and perioperatively for both minor and major surgical stress [1] with recommendations for $\mathrm{CAH}$ mirroring those for adrenal insufficiency [3]. Despite accurate diagnosis and optimal treatment, children

(c) The Author(s). 2018 Open Access This article is distributed under the terms of the Creative Commons Attribution 4.0 International License (http://creativecommons.org/licenses/by/4.0/), which permits unrestricted use, distribution, and reproduction in any medium, provided you give appropriate credit to the original author(s) and the source, provide a link to the Creative Commons license, and indicate if changes were made. The Creative Commons Public Domain Dedication waiver (http://creativecommons.org/publicdomain/zero/1.0/) applies to the data made available in this article, unless otherwise stated. 
with $\mathrm{CAH}$ have been found to have a mortality rate 3 times greater than unaffected children [4].

Currently, there remains debate among some clinicians as to whether perioperative stress-dose supraphysiologic glucocorticoids are required for all surgical procedures and general anesthesia. This includes debate as to replacement for what types of surgery, the optimal timing of administration, and the frequency of dosing. A Cochrane review of adult adrenal insufficiency studies, due to small numbers, was 'unable to support or refute the use of supplemental perioperative steroids for patients with adrenal insufficiency during surgery [5].' Even less evidence exists in the pediatric population. Advocates for the use of perioperative 'stress dose' steroids cite the potential catastrophic harms of adrenal crisis while those against cite side effect accumulation from repeated treatment with high dose glucocorticoids and the lack of proven benefit particularly for minor procedures.

The purpose of this study was to compare and contrast practice patterns and beliefs of pediatric anesthesiologists and pediatric endocrinologists in Canada regarding perioperative corticosteroid management in patients with $\mathrm{CAH}$.

\section{Methods}

Local research ethics board approval was obtained for surveys to both anesthesia and endocrinology. An electronic cross-sectional survey was distributed via the Canadian Pediatric Anesthesia Society (CPAS) members' email list and via the Canadian Pediatric Endocrinology Group's (CPEG) email list (See Additional files 1 and 2 for anesthesia and endocrine surveys, respectively). The initial email invitation was followed by two additional invitations to complete the survey.

Response frequencies with proportions were calculated for the sample as a whole and by professional group. Responses to questions answered by both groups were compared using the Chi-square test or Fisher's exact test, the latter when expected cell sizes were less than 5 . Alpha was set at 0.05. Analysis was undertaken using SAS, version 9.4 (SAS Institute Inc., Cary, NC, USA).

\section{Results}

We received 49 responses from anesthesiology and 37 responses from pediatric endocrinology. Though definitive recipient denominators could not be ascertained, respective listserv managers approximated 300 anesthesiology members $(\sim 16.3 \%$ response rate) and 85 pediatric endocrinology members ( $\sim 43.5 \%$ response rate).

Anesthesia respondents were predominantly male (64\%), worked in a university/teaching site (86\%), had over 15 years' experience (61\%), and worked in a predominantly pediatric practice $(83 \%)$. Ninety-two percent of anesthesiologists reported to see less than 6 patients with $\mathrm{CAH}$ per year.

Endocrinology respondents were predominantly female (76\%), worked in a university/teaching site (92\%), and reported predominant ranges of experience of either less than 5 years or greater than 15 years (39 and 36\%, respectively).

Endocrinologist were more likely to report being aware of and report to following guidelines for the perioperative management of primary adrenal insufficiency compared with anesthesiologists ( $84 \%$ vs $51 \%$, respectively; $p=0.001$ ) with $68 \%$ of endocrinologists who used guidelines reported that they use locally established guidelines (Table 1).

Anesthesiology respondents reported they were less likely to provide stress-dose steroids for a cystoscopy compared with endocrinology respondents (45\% vs $92 \%$ respectively, $p<0.0001)$. Only $8 \%$ of pediatric endocrinologists responded that they would not recommend stress dosing, and instead recommend continuation of daily glucocorticoid replacement (Table 1). Twenty-one percent of anesthesiologists reported they would not follow stress-dose guidelines for patients undergoing laparotomy. More than half of endocrinologists (57\%) reported that they would recommend stress dose steroids for all patient with $\mathrm{CAH}$ undergoing anesthesia, while the remaining reported they would base recommendations on the type of procedure (13.5\%), CAH severity (13.5\%) or both (16\%) (See Table 2).

Anesthesiologists were more likely than endocrinologists to be concerned about repeated, single high dose steroid exposures in patients with $\mathrm{CAH}$ undergoing anesthesia (36\% vs. $14 \%, p<0.02)$ with many reporting that they felt stress dose guidelines led to overtreatment.

\section{Discussion}

Our survey of Canadian pediatric endocrinologists and pediatric anesthesiologists or anesthesiologists with pediatrics in their practice demonstrates a difference in reported practices regarding perioperative glucocorticoid administration in children with $\mathrm{CAH}$. Pediatric endocrinologists were more likely to recommend glucocorticoid 'stress dose' coverage perioperatively for both less and more invasive procedures in children with $\mathrm{CAH}$.

Determining the ideal time, amount and duration of stress dose glucocorticoids for patients with primary adrenal insufficiency is largely unknown and research into this area has been conflicting or absent. Owing to small patient numbers, different glucocorticoid formulations, a variety of underlying causes of adrenal insufficiency and varying degrees of surgical stress, conclusive evidence to provide clear recommendations has been sparse. As a result, current practice guidelines are based 
Table 1 Overall frequencies and comparison of characteristics between pediatric endocrinologists and anesthesiologists

\begin{tabular}{|c|c|c|c|c|}
\hline Demographics, n (\%) & Combined $(N=86)$ & $\begin{array}{l}\text { Anesthesiologists } \\
(n=49,57 \%)\end{array}$ & Endocrinologists $(n=37,43 \%)$ & $P$-value \\
\hline \multicolumn{5}{|l|}{ Age } \\
\hline $25-35$ years & $10(11.6)$ & $1(2.0)$ & $9(24.3)$ & \multirow[t]{3}{*}{0.002} \\
\hline $36-50$ years & $41(47.7)$ & $23(46.9)$ & $18(48.7)$ & \\
\hline$>50$ years & $35(40.7)$ & $25(51.0)$ & $10(27.0)$ & \\
\hline \multicolumn{5}{|l|}{ Sex } \\
\hline Male & $39(46.4)$ & $30(63.8)$ & $9(24.3)$ & \multirow[t]{2}{*}{0.0003} \\
\hline Female & $45(53.6)$ & $17(36.2)$ & $28(75.7)$ & \\
\hline \multicolumn{5}{|c|}{ Practice characteristics, n (\%) } \\
\hline \multicolumn{5}{|l|}{ Practice type } \\
\hline University/ teaching & $76(88.4)$ & $42(85.7)$ & $34(91.9)$ & \multirow[t]{2}{*}{0.50} \\
\hline Other & $10(11.6)$ & $7(14.3)$ & $3(8.1)$ & \\
\hline \multicolumn{5}{|l|}{ Years in practice } \\
\hline$<5$ & $13(15.9)$ & 0 & $13(39.4)$ & \multirow[t]{4}{*}{$<0.0001$} \\
\hline $5-10$ & $17(20.7)$ & $12(24.5)$ & $5(15.1)$ & \\
\hline $11-15$ & $10(12.2)$ & $7(14.3)$ & $3(9.1)$ & \\
\hline$>15$ & $42(51.2)$ & $30(61.2)$ & $12(36.4)$ & \\
\hline \multicolumn{5}{|c|}{ Congenital adrenal hyperplasia in practice } \\
\hline \multicolumn{5}{|c|}{ Administer stress dose steroids for cystoscopy } \\
\hline Yes & $55(65.5)$ & $21(44.7)$ & $34(91.9)$ & \multirow[t]{2}{*}{$<0.0001$} \\
\hline No & $29(34.5)$ & $26(55.3)$ & $3(8.1)$ & \\
\hline \multicolumn{5}{|c|}{ Concerned about repeated single high dose steroids } \\
\hline Yes & $22(26.2)$ & $17(36.2)$ & $5(13.5)$ & \multirow[t]{2}{*}{0.019} \\
\hline No & $62(73.8)$ & $30(63.8)$ & $32(86.5)$ & \\
\hline \multicolumn{5}{|c|}{ Consult opposite specialty } \\
\hline Always & $20(23.3)$ & $14(28.6)$ & $6(16.2)$ & \multirow[t]{4}{*}{0.16} \\
\hline Frequently & $18(20.9)$ & $12(24.5)$ & $6(16.2)$ & \\
\hline Occasionally & $25(29.1)$ & $14(28.6)$ & $11(29.7)$ & \\
\hline Never & $23(26.7)$ & $9(18.4)$ & $14(37.8)$ & \\
\hline \multicolumn{5}{|c|}{ See endocrinology before surgery } \\
\hline Sometimes & $8(9.5)$ & $5(10.6)$ & $3(8.1)$ & \multirow[t]{2}{*}{0.99} \\
\hline Yes & $76(90.5)$ & $42(89.4)$ & $34(91.9)$ & \\
\hline \multicolumn{5}{|c|}{ Follow guidelines for stress dose decision } \\
\hline Yes & $56(65.1)$ & $25(51.0)$ & $31(83.8)^{b}$ & \multirow[t]{2}{*}{0.001} \\
\hline No & $30(34.9)$ & $24(49.0)$ & $6(16.2)$ & \\
\hline
\end{tabular}

${ }^{a}$ Comparisons by Chi-square test or Fisher's exact test

${ }^{\mathrm{b}}$ Guideline type: Local centre guidelines $n=21(67.7 \%)$, published clinical practice guidelines $n=7(22.6 \%)$, other $n=3(9.7 \%)$. Frequencies in variable categories do not always sum the totals because of missing data

more so on expert opinion and may be aimed to safeguard against worst case scenarios [6].

Indications for stress-dose supraphysiologic glucocorticoids in $\mathrm{CAH}$ have evolved over recent years, particularly during times of 'normal' stress, such as school examinations, emotional stress, or exercise. Studies examining high intensity exercise, for example, have demonstrated that additional supraphysiologic glucocorticoid administration provided no clinically meaningful benefit to hormonal, metabolic, or cardiorespiratory outcomes [7]. In the surgical patient with $\mathrm{CAH}$, the impact of fasting, with its potential for stress response, hypoglycemia and dehydration, has not been studied.

A number of studies have used healthy children to document hormonal responses to anesthesia and surgery. Research by $\mathrm{Hsu}$ et al. demonstrated a 3-fold increase in 
Table 2 Group-specific responses of anesthesiologists and pediatric endocrinologists regarding perioperative care of pediatric congenital adrenal hyperplasia patients

\begin{tabular}{lr}
\hline & Anesthesiologists $n=48$ \\
\hline Congenital adrenal hyperplasia in practice, $n(\%)$ & Endocrinologists $n$ \\
Number of CAH patients in endocrinology practice & $2(5.4)$ \\
None & $16(43.2)$ \\
$1-5$ & $8(21.6)$ \\
$6-10$ & $4(10.8)$ \\
$11-15$ & $7(18.9)$ \\
$>15$ &
\end{tabular}

Number of pediatric $\mathrm{CAH}$ patients in anesthesia practice per year

$$
\leq 5
$$

$6-12$

Percentage of practice that involves pediatric anesthesia

$$
1-25
$$

$26-50$

$51-75$

$76-100$

Pediatric congenital adrenal hyperplasia management, n (\%)

Common to see $\mathrm{CAH}$ patients regarding stress dose prior to surgery

Yes

Sometimes

Consult another anesthesiologist regarding stress dosing

Frequently ( $>50 \%$ of the time)

Occasionally ( $<50 \%$ of the time)

$15(31.3)$

Never

$30(62.5)$

Frequency of consult to anesthesiologist regarding stress dose

Always

Frequently

Occasionally

Never

Frequency of consult to endocrinologist regarding stress dose

$\begin{array}{ll}\text { Always } & 14(28.6) \\ \text { Frequently } & 12(24.5) \\ \text { Occasionally } & 14(28.6) \\ \text { Never } & 9(18.4)\end{array}$

Endocrinology referral common at home institution for any surgery in children with $\mathrm{CAH}$

Yes

Unsure

Recommend corticosteroid stress dose for children with CAH undergoing anesthesia

Always

Severity dependent

Procedure dependent

$5(13.5)$

Severity and procedure dependent

$6(16.2)$

Minor procedure recommendation/management (e.g. cystoscopy), n (\%)

Recommended dosing: 
Table 2 Group-specific responses of anesthesiologists and pediatric endocrinologists regarding perioperative care of pediatric congenital adrenal hyperplasia patients (Continued)

\begin{tabular}{|c|c|c|}
\hline & Anesthesiologists $n=48$ & Endocrinologists $n=37$ \\
\hline Mild stress dosing ( $20-40 \mathrm{mg} / \mathrm{m}^{2}$ of $\mathrm{HC}$ equivalent) & & $26(70.3)$ \\
\hline High dose (50-100 mg/m² of HC equivalent) & & $8(21.6)$ \\
\hline Baseline therapy & & $3(8.1)$ \\
\hline \multicolumn{3}{|l|}{ Follow guidelines for minor procedures? } \\
\hline Yes & $21(44.7)$ & \\
\hline No & $26(55.3)$ & \\
\hline \multicolumn{3}{|c|}{ Steroid dosing if typically using dexamethasone for prevention of PONV } \\
\hline Omit dexamethasone, give stress dose & $23(48.9)$ & \\
\hline Give dexamethasone + baseline steroid & $12(25.5)$ & \\
\hline Give dexamethasone + stress dose & $6(12.8)$ & \\
\hline Other & $6(12.8)$ & \\
\hline \multicolumn{3}{|l|}{ Major procedure management (e.g. laparotomy), n (\%) } \\
\hline \multicolumn{3}{|l|}{ Follow guidelines } \\
\hline Yes & $37(78.7)$ & \\
\hline No & $10(21.3)$ & \\
\hline
\end{tabular}

CAH congenital adrenal hyperplasia, $H C$ Hydrocortisone, PONV post-operative nausea and vomiting

salivary cortisol concentrations in 110 healthy children following surgery or sedation [8]. Cortisol levels were highest in the recovery phase after the procedure was completed; however, levels were not influenced by degree of sedation achieved nor type of procedure performed. Some studies have demonstrated a graded response of cortisol production to the degree of surgical stress [9], while other studies have attributed this to anesthesia reversal and recovery and not the surgical trauma itself [10]. Anesthesia for minimally invasive procedures and medical imaging has been shown to result in minimal cortisol excursions in healthy children [11, 12]. Taken together, these studies are certainly influenced by medication choices and anesthetic techniques which have changed significantly over recent years yielding significant effects on physiologic response to surgery and anesthesia [13]. Given the heterogeneity in populations studied, methods employed, degrees of surgical intervention, and sedation techniques, it is unclear whether cortisol excursion following anesthesia and surgery is merely a biochemical, physiologic response or whether it is important for patient recovery [8].

Within adult practice, a growing tendency to maintain a patient's maintenance (physiologic) dose of steroids throughout the surgical period in those with adrenal insufficiency secondary to exogenous suppression has elicited much controversy. Recent reviews in adults with adrenal insufficiency secondary to chronic corticosteroid use have suggested that patients do not require stress dose steroids for surgery [14]. The theoretic rationale for this has been that patients with secondary suppression are more likely to demonstrate an endogenous hypothalamic-pituitary-adrenal axis response to severe physiological stresses. However, it is important to note that authors have been careful to point out that these reviews do not apply to causes of primary adrenal insufficiency, such as $\mathrm{CAH}$ or Addison's disease, whereby no endogenous glucocorticoid production is possible, even under marked physiologic stress. Proponents of withholding stress dose steroids in adults with secondary suppression have been careful to clarify this difference and, thus recommend coverage in all patients with primary adrenal insufficiency [14]. Furthermore, cases of adrenal crisis in primary adrenal insufficiency have emerged following the adoption of some of these practices associated with adrenal insufficiency secondary to exogenous suppression [15].

Current Endocrine Society guidelines endorse the use of stress dose (supraphysiologic) steroid graded on the degree of surgical stress (See Table 3) [1]. These recommendations were largely adapted from expert opinion and their intent was not to cover surgical stress per-se, but rather to cover in case of unforeseen complications. As a result, the "dose increase is not intended to mimic the median cortisol increase in healthy subjects during such procedures. Instead, it is intended to mimic the maximum cortisol increase, which may occur in euadrenal subjects triggered during these procedures, potentially induced by some unforeseen events (e.g. postoperative bleeding) [6]." The rationale for prophylactically providing these stress dose (supraphysiologic) glucocorticoids is to pre-emptively 
Table 3 Management of pediatric adrenal insufficiency in specific situations. Adapted from [1]

\begin{tabular}{|c|c|}
\hline Condition & Suggested Action \\
\hline \multirow{2}{*}{$\begin{array}{l}\text { Home management of illness with fever. } \\
\text { Unable to tolerate oral medications due to } \\
\text { gastroenteritis or trauma }\end{array}$} & $\begin{array}{l}\text { Hydrocortisone replacement doses doubled }\left(>38^{\circ} \mathrm{C} \text { ) or tripled }\left(>39^{\circ} \mathrm{C}\right) \text { until recovery }\right. \\
\text { (usually } 2 \text { to } 3 \text { days); increased consumption of electrolyte containing fluids as tolerated }\end{array}$ \\
\hline & $\begin{array}{l}\text { IM/SC Hydrocortisone } 50 \mathrm{mg} / \mathrm{m}^{2} \text { or estimate; infants } 25 \text { mg, school-aged children } 50 \text { mg, } \\
\text { adolescents } 100 \mathrm{mg} \text {. }\end{array}$ \\
\hline Minor to moderate surgical stress & $\begin{array}{l}\text { Intramuscular/Intravenous Hydrocortisone } 50 \mathrm{mg} / \mathrm{m}^{2} \text { or hydrocortisone replacement doses } \\
\text { doubled or tripled }\end{array}$ \\
\hline \multirow[t]{3}{*}{$\begin{array}{l}\text { Major Surgical Stress with general anesthesia, trauma, } \\
\text { or diseases that require intensive care }\end{array}$} & $\begin{array}{l}\text { Hydrocortisone } 50 \mathrm{mg} / \mathrm{m} 2 \text { intravenous followed by hydrocortisone } 50-100 \mathrm{mg} / \mathrm{m}^{2} / \mathrm{d} \text { divided } \\
\text { q6 h }\end{array}$ \\
\hline & Weight-appropriate continuous intravenous fluids (dextrose containing) \\
\hline & Rapid tapering and switch to oral regimen depending on clinical state \\
\hline \multirow[t]{4}{*}{ Acute adrenal crisis } & $\begin{array}{l}\text { Rapid bolus of normal saline }(0.9 \%) 20 \mathrm{~mL} / \mathrm{kg} \text {. Can repeat up to a total of } 60 \mathrm{~mL} / \mathrm{kg} \text { within } 1 \mathrm{~h} \\
\text { for shock. }\end{array}$ \\
\hline & $\begin{array}{l}\text { Hydrocortisone } 50-100 \mathrm{mg} / \mathrm{m} 2 \text { bolus followed by hydrocortisone } 50-100 \mathrm{mg} / \mathrm{m}^{2} / \mathrm{d} \\
\text { divided q } 6 \mathrm{~h}\end{array}$ \\
\hline & $\begin{array}{l}\text { For hypoglycemia: dextrose } 0.5-1 \mathrm{~g} / \mathrm{kg} \text { of dextrose or } 2-4 \mathrm{~mL} / \mathrm{kg} \text { of } \mathrm{D} 25 \mathrm{~W} \text { (maximum single } \\
\text { dose } 25 \mathrm{~g} \text { ) infused slowly at rate of } 2 \text { to } 3 \mathrm{~mL} / \mathrm{min} \text {. Alternatively, } 5-10 \mathrm{~mL} / \mathrm{kg} \text { of D } 10 \mathrm{~W} \text { for } \\
\text { children }<12 \text { y old }\end{array}$ \\
\hline & Cardiac monitoring: Rapid tapering and switch to oral regimen depending on clinical state \\
\hline
\end{tabular}

prevent clinical deterioration as euadrenal patients would have an immediate response to unforeseen circumstance while adrenal insufficient patients would be delayed until after clinical decompensation, physician recognition, glucocorticoid administration and its onset of action. In our survey, we found that $21 \%$ of anesthesiologist respondents reported they would not administer stress dose steroids for those patients undergoing laparotomy. Unfortunately, from our questionnaire, we did not gather the rationale as to why these physicians would omit stress dose treatment in such a scenario.

Given the rationale for treatment recommendations, one may stand to argue whether low-stress procedures with low risk of complications indeed require stress dose (supraphysiologic) prophylactic glucocorticoid doses (i.e. cystoscopy or medical imaging). Over half of the responding anesthesiologists (55\%) reported they would not provide supraphysiologic glucocorticoids for these clinical situations, as compared with $8 \%$ of endocrinologists. While it is known that long term supraphysiologic steroid administration is associated with many iatrogenic medical complications, the short duration and relatively small (comparative) doses used perioperatively have not been demonstrated to cause harm.

From our data, anesthesiologists were more likely to be concerned about side effects from repeated, single doses of high dose glucocorticoids; however, these concerns merit clinical reflection given that many anesthesiologists prophylactically use dexamethasone for the prevention of post-operative nausea and vomiting at glucocorticoid equivalent doses that are at least as high or greater than those recommended by single dose perioperative stress dose guidelines.

\section{Limitations}

This study relied upon voluntary response from a national digital mail out to the prominent Canadian organizations for pediatric anesthesiology and pediatric endocrinology. As a result, the exact total sample size and thus the proportion of responders is not definite.

\section{Conclusions}

This physician survey was performed to highlight a suspected difference in practices between pediatric anesthesia and pediatric endocrine colleagues ultimately caring for the same patient cohort and to begin a dialogue among specialty groups. While the authors of this paper still advocate for the use of perioperative stress dose glucocorticoid prescription for primary adrenal insufficiency in pediatrics as per the limited guidelines currently available, it must be recognized that available literature is sparse and further study to guide evidence based recommendations are still required. This survey demonstrates a clear discrepancy in practice patterns and highlights the need for further discussion between care providers. The risk of adverse effects from prophylactic stress dose (supraphysiologic) steroids are trivial. While the risks associated with foregoing prophylactic therapy are similarly low, the potential rare outcome in unforeseen circumstances may be catastrophic.

\section{Additional files}

Additional file 1: Survey questions sent to Canadian Pediatric Anesthesia Society (CPAS) members. (DOCX $16 \mathrm{~kb}$ )

Additional file 2: Survey questions sent to Canadian Pediatric Endocrine Group (CPEG) members. (DOCX $17 \mathrm{~kb}$ ) 


\section{Abbreviations}

21-OH: 21-hydroxylase; CAH: Congenital adrenal hyperplasia; HC: Hydrocortisone; PONV: Post-operative nausea and vomiting

\section{Acknowledgements}

The authors would like to acknowledge the contributions of Jennifer O'Brien, Erin Prosser-Loose, Rhonda Bryce, and Dr. Josephine Ho. Additionally, the authors are thankful for the assistance from the Canadian Pediatric Anesthesia Society (CPAS) and the Canadian Pediatric Endocrine Group (CPEG) for distributing the survey.

\section{Authors' contributions}

$\mathrm{MN}, \mathrm{HG}, \mathrm{MI}$ and $\mathrm{KU}$ were responsible for survey creation and sendout. MN performed data analysis. PM performed statistical analysis. MN drafted the manuscript and all authors contributed to accuracy and editing of data. All authors read and approved the final manuscript.

\section{Ethics approval and consent to participate}

Appropriate Research Ethics Board (REB) approval was obtained through the University of Saskatchewan for this study.

\section{Consent for publication}

Not applicable

\section{Competing interests}

The authors declare that they have no competing interests.

\section{Publisher's Note}

Springer Nature remains neutral with regard to jurisdictional claims in published maps and institutional affiliations.

\section{Author details}

'Division of Pediatric Endocrinology, Department of Pediatrics, College of Medicine, University of Saskatchewan, Royal University Hospital, 103 Hospital Drive, Saskatoon, SK S7N OW8, Canada. ${ }^{2}$ Department of Anesthesiology, Perioperative Medicine and Pain Management, University of Saskatchewan, Saskatoon, Canada. ${ }^{3}$ Clinical Research Support Unit, College of Medicine, University of Saskatchewan, Saskatoon, Canada.

Received: 18 June 2018 Accepted: 26 August 2018

Published online: 10 September 2018

\section{References}

1. Bornstein SR, Allolio B, Arlt W, Barthel A, Don-Wauchope A, Hammer $G D$, et al. Diagnosis and treatment of primary adrenal insufficiency: an endocrine society clinical practice guideline. J Clin Endocrinol Metab. 2016;101(2):364-89.

2. Nimkarn S, Gangishetti PK, Yau M, New MI. 21-hydroxylase-deficient congenital adrenal hyperplasia. In: Pagon RA, Adam MP, Ardinger $\mathrm{HH}_{4}$ Wallace SE, Amemiya A, Bean LJ, et al., editors. GeneReviews( $\left.{ }^{\circledR}\right)$ [Internet]. Seattle: University of Washington, Seattle; 1993. Available from: http://www. ncbi.nlm.nih.gov/books/NBK1171/. Cited 10 July 2017.

3. Parsa AA, New MI. Steroid 21-hydroxylase deficiency in congenital adrenal hyperplasia. J Steroid Biochem Mol Biol. 2017;165:2-11. Part A

4. Swerdlow AJ, Higgins CD, Brook CG, Dunger DB, Hindmarsh PC, Price DA, et al. Mortality in patients with congenital adrenal hyperplasia: a cohort study. J Pediatr. 1998:133(4):516-20.

5. Yong SL, Coulthard P, Wrzosek A. Supplemental perioperative steroids for surgical patients with adrenal insufficiency. Cochrane Database Syst Rev. 2012;12:CD005367.

6. Allolio B. Extensive expertise in endocrinology. Adrenal crisis. Eur J Endocrinol. 2015;172(3):R115-24.

7. Weise M, Drinkard B, Mehlinger SL, Holzer SM, Eisenhofer G, Charmandari E, et al. Stress dose of hydrocortisone is not beneficial in patients with classic congenital adrenal hyperplasia undergoing short-term, high-intensity exercise. J Clin Endocrinol Metab. 2004:89(8):3679-84.

8. Hsu AA, von Elten K, Chan D, Flynn T, Walker K, Barnhill J, et al. Characterization of the cortisol stress response to sedation and anesthesia in children. J Clin Endocrinol Metab. 2012;97(10):E1830-5.
9. Chernow B, Alexander HR, Smallridge RC, Thompson WR, Cook D, Beardsley $D$, et al. Hormonal responses to graded surgical stress. Arch Intern Med. 1987;147(7):1273-8.

10. Udelsman R, Norton JA, Jelenich SE, Goldstein DS, Linehan WM, Loriaux DL, et al. Responses of the hypothalamic-pituitary-adrenal and renin-angiotensin axes and the sympathetic system during controlled surgical and anesthetic stress. J Clin Endocrinol Metab. 1987;64(5):986-94.

11. Taylor LK, Auchus RJ, Baskin LS, Miller WL. Cortisol response to operative stress with anesthesia in healthy children. J Clin Endocrinol Metab. 2013; 98(9):3687-93.

12. Rains PC, Rampersad N, De Lima J, Murrell D, Kinchington D, Lee JW, et al. Cortisol response to general anaesthesia for medical imaging in children. Clin Endocrinol. 2009;71(6):834-9.

13. Wolf AR, Doyle E, Thomas E. Modifying infant stress responses to major surgery: spinal vs extradural vs opioid analgesia. Paediatr Anaesth. 1998; 8(4):305-11.

14. Marik PE, Varon J. Requirement of perioperative stress doses of corticosteroids: a systematic review of the literature. Arch Surg. 2008; 143(12):1222-6.

15. Tan J, Zavala A, Hagan KB, Van Meter A, Williams UU, Zhang W, et al. Perioperative severe hypotension in a patient with multiple endocrine neoplasia type IIb and bilateral adrenalectomies: time to review the evidence for stress dose steroids. Case Rep Anesthesiol. 2016;2016:8153296.
Ready to submit your research? Choose BMC and benefit from:

- fast, convenient online submission

- thorough peer review by experienced researchers in your field

- rapid publication on acceptance

- support for research data, including large and complex data types

- gold Open Access which fosters wider collaboration and increased citations

- maximum visibility for your research: over $100 \mathrm{M}$ website views per year

At $\mathrm{BMC}$, research is always in progress.

Learn more biomedcentral.com/submissions 